\title{
The Symmetry of Rational Requirements
}

\author{
Jonathan Way \\ University of Stirling
}

It is often thought that one of the most basic, or at least obvious, features of rationality is that it involves a kind of coherence. Certain patterns of attitudes do not fit together well, and it is a mark of the rational agent that he avoids these patterns. Plausible examples include akrasia (believing you ought to A, but not intending to A), meansend incoherence (intending to $\mathrm{E}$, believing that $\mathrm{M}$ is necessary for $\mathrm{E}$, but not intending to M), and inconsistency (in belief, or in intention). I will call patterns of this sort local irrationalities: they are patterns of attitudes that irrational no matter the rest of your psychology.

On a natural picture, local irrationalities correspond to rational requirements: there are rational requirements against inconsistency, means-end incoherence, akrasia, and so on. In general, when you are locally irrational, that is because you violate a rational requirement. ${ }^{1}$ However, amongst those who accept this picture, there is an important disagreement between those who accept a Wide-Scope view of rational requirements, and those who accept a Narrow-Scope view. In this paper, I want to defend the Wide-Scope view against an important line of objection. I need to begin by explaining the debate.

Rational requirements are naturally formulated as conditionals: if you believe that you ought to A, rationality requires that you intend to A; if you believe that $\mathrm{p}$ and believe that if $\mathrm{p}$ then $\mathrm{q}$, rationality requires that you believe that $\mathrm{p}$. However, these

\footnotetext{
${ }^{1}$ Broome 2005, Kolodny 2005. For alternative ways of thinking about local irrationalities, see Raz 2005 and Kolodny $2007 \mathrm{~b}$.
} 
claims can be understood in two ways. The Narrow-Scope view read them as their surface form suggests: as conditionals whose antecedent mentions an attitude or two (the 'antecedent attitudes'), and whose consequent says that a further attitude (the 'consequent attitude') is rationally required. So - to take the requirements that will be my main concern in this paper - we have:

(Enkrasia-N) If you believe that you ought to $\mathrm{A}$, then rationality requires that you intend to $\mathrm{A}$.

(Means-End-N) If you intend to $\mathrm{E}$ and believe that $\mathrm{M}$ is necessary for $\mathrm{E}$, then rationality requires that you intend to $\mathrm{M}$.

(Closure-N) If you believe that $\mathrm{p}$ and believe that if $\mathrm{p}$ then $\mathrm{q}$, then rationality requires that you believe q.

By contrast, the Wide-Scope view hold that rational requirements are requirements to conform to a conditional. ${ }^{2}$ So the above requirements become:

(Enkrasia-W) Rationality requires that [if you believe you ought to A, you intend to $\mathrm{A}]$.

(Means-End-W) Rationality requires that [if you intend to $\mathrm{E}$ and believe that $\mathrm{M}$ is necessary for $\mathrm{E}$, you intend to $\mathrm{M}]$.

(Closure-W) Rationality requires that [if you believe that $\mathrm{p}$ and believe that if $p$ then $q$, you believe $q]^{3}$

\footnotetext{
${ }^{2}$ The most influential defender of the Wide-Scope view is John Broome (1999, 2005, 2007b).

${ }^{3}$ These statements are first approximations. For some of the required modifications, see Broome 2005. Following Broome, I state these requirements as if 'rationally required' is a propositional operator. However, the debate between the Wide- and Narrow-Scope views does not turn on this.
} 
The Wide-Scope view is typically motivated by a problem for the Narrow-Scope view. Narrow-Scope requirements are susceptible to clear counter-examples. We can construct such examples by considering cases in which one of the antecedent attitudes is itself irrational. For example, consider a case in which your antecedent belief is a product of wishful thinking, or in which you intend to do something which is obviously crazy. In such a case, it is implausible that rationality requires you to have the consequent attitude - on the contrary, the consequent attitude would itself be irrational. We might also put the point this way: if you give up an irrational antecedent attitude and do not form the consequent attitude, it is implausible that you have thereby failed to do something rationality required of you. ${ }^{4}$

Wide-Scope requirements are not susceptible to such counter-examples. You comply with a Wide-Scope requirement so long as you don't have the antecedent attitudes without the consequent attitude. For instance, you comply with Enkrasia-W so long as you don't believe you ought to A without intending to A. Rationality requires you simply to avoid that combination. So Wide-Scope requirements don't imply that if you have the antecedent attitudes, you are rationally required to have the consequent attitude. And so they don't imply that if you have an irrational antecedent attitude, you are rationally required to have the consequent attitude. Nor do they imply that if you give up an irrational antecedent attitude, you have failed to do something rationality required of you.

The Wide-Scope view has this advantage over the Narrow because its requirements are symmetrical. Wide-Scope requirements do not discriminate between the different ways in which you might avoid irrationality. For example, you avoid

\footnotetext{
${ }^{4}$ For this way of putting the problem, see Brunero 2010: 35. Broome (1999) offers this sort of objection to the claim that you ought or have reason to comply with Narrow-Scope requirements. But the objection seems to me to have force against the requirements simply as stated. For argument to this effect, see Brunero 2010: 34-44, Hussain ms, section 4.1, and Reisner 2009: 247-8.
} 
akrasia (with respect to the belief that you ought to A) if either you intend to A or if you do not believe you ought to A. The Wide-Scope view says that both of these states constitute compliance with Enkrasia-W. Parallel points hold for the other WideScope requirements.

The symmetry of Wide-Scope requirements is thus the main reason the WideScope view seems to be an improvement over the Narrow. Yet a number of writers have objected that it is also where the Wide-Scope view goes wrong. Their concern is that the Wide-Scope view ignores important asymmetries that the Narrow-Scope view captures. To get a feel for this objection, consider a case in which you are akratic - for some A, you believe that you ought to A but do not intend to A. Now you will certainly no longer be akratic if either you form the intention to A or you give up the belief that you ought to A. But we might feel that these responses are not on a par. We might want to say that forming the intention is the right way to respond to akrasia, and giving up the belief is the wrong way. And we might have similar thoughts about some of the other local irrationalities. The worry is that the symmetry of Wide-Scope requirements leaves no room for these thoughts.

The aim of this paper is to defend the Wide-Scope view against this asymmetry objection. I will consider two versions of the objection, one due to Mark Schroeder and one to Niko Kolodny. ${ }^{5}$ I will argue that while both authors draw our attention to a genuine asymmetry, neither shows that their asymmetry is incompatible with the Wide-Scope view. Once we are clear about what the Wide-Scope view is committed to - and, importantly, what it is not - we can see how the Wide-Scoper can respond to Schroeder and Kolodny's arguments. The symmetry of Wide-Scope rational requirements should not lead us to reject the Wide-Scope view.

\footnotetext{
${ }^{5}$ Schroeder's version of the objection is endorsed by Finlay forthcoming, section 2. Korsgaard 2009 also offers a version of the objection, which is closer to Kolodny's.
} 


\section{The Wide-Scope View}

I understand the Wide-Scope view to make two main claims. First, it accepts Wide-

Scope rational requirements, such as those above, which forbid local irrationalities.

Second, it maintains that local irrationalities are irrational as such. They are not irrational only because they involve independently irrational attitudes. This is important because the Narrow-Scope view also holds that local irrationalities are irrational. For instance, the Narrow-Scope view holds that akrasia is irrational because the akratic agent lacks an intention that rationality requires. The distinctive WideScope claim is that local irrationalities are irrational even if none of the elements constituting them is irrational. The problem is in the combination.

These two claims give us a version of the Wide-Scope view that is modest, in at least two respects. First, the view allows that you are sometimes rationally required to have particular attitudes. It is quite consistent with Enkrasia-W, for instance, that sometimes when you believe you ought to A, you are rationally required to intend to A. I will assume that there are occasions on which you are so required. ${ }^{6}$ Second, the Wide-Scope view allows that rationality may involve more than mere compliance with a set of Wide-Scope requirements along the lines of those above. I will suggest that compliance with such requirements is at most a part of what it is to be rational. Being rational also involves forming, holding and revising attitudes for appropriate reasons. So Wide-Scope requirements must be supplemented with principles giving

\footnotetext{
${ }^{6}$ Brunero (2010) takes a similar line. Some Wide-Scopers are more ambitious. For example, Broome (2005: 323) claims that there are only 'rare exceptions' to the claim that 'rational requirements generally have wide-scope'. The only example he gives is of the requirement not to believe contradictory propositions.
} 
conditions under which attitudes are appropriately formed, held and revised. I will call such principles basing principles.

This point may require clarification. Parties to this debate often deny that there is a close connection between rationality and reasons. For instance, Kolodny writes, "When we say "you ought to" in the sense of "it would be irrational of you not to," we seem to be saying something about the relation between your attitudes, viewed in abstraction from the reasons for them' (2005: 509, original italics). However, here Kolodny is talking about objective normative reasons: facts, of which an agent may be unaware, that favor an attitude. By contrast, my claim is that there is a connection between rationality and the reasons for which agents hold attitudes. These reasons are simply the type of thing that can figure in a certain type of explanation: 'Lindsay intends to leave because the game is starting', 'Daniel believes he will pass because he believes he has a copy of the test', and so on. It is hard to see how it could be denied that reasons, in this sense, are relevant to rationality.

Another clarification is worth making. As the two examples illustrate, explanations of this sort sometimes cite considerations - putative facts - and sometimes cite other attitudes. In the first case, we cite the consideration in light of which the agent believes or intends. This is sometimes called the 'agent's reason' (Darwall 1983: 32 and passim). In the second case, we cite the psychological ground or basis for the belief or intention. Although these relations are closely connected, I take it that basing principles will be explicitly concerned with the latter. Basing principles specify whether an attitude, or set of attitudes, is an appropriate basis for another attitude.

The two dimensions of modesty just outlined allow us to see, in outline, how the Wide-Scope view can respond to the asymmetry objection. The first tells us 
something about what the objection must be, if it is to be successful. The problem cannot simply be that there are cases in which you are rationally required to have a particular attitude. The Wide-Scope view can accept this. The objection must then rest on an asymmetry that is independent of the rational permissibility of the antecedent and consequent attitudes. One way this could be - and as far as I can tell the only way - is if there are asymmetries in the different reasons for which you might form and revise your attitudes so as to comply with Wide-Scope requirements. But the second dimension of modesty shows us how to accommodate this. Wide-Scope requirements are not directly concerned with basing, and so need to be supplemented with independent basing principles. But then we can expect those principles to explain this type of asymmetry.

I now turn to Schroeder's objection. I will argue that the strategy just outlined allows the Wide-Scoper to reply. ${ }^{7}$

\section{The Rationalization Asymmetry}

Here is Schroeder's statement of the asymmetry objection, in discussing a version of Enkrasia- $\mathrm{W}^{8}$ :

\footnotetext{
The first problem for Wide-Scoping is that it is symmetric. It doesn't distinguish between acting in accordance with your moral beliefs and adopting moral beliefs in accordance with your actions, and as a result it fails to distinguish between following your conscience and the distinctive vice of rationalization. Rationalization is the vice of changing your beliefs about what you ought to do, because you are not going to do it, anyway. According to the Wide-Scope view,
}

\footnotetext{
${ }^{7}$ John Broome independently offers a similar response to Schroeder in a draft book manuscript.

${ }^{8}$ For the most part, Schroeder and Kolodny focus on Enkrasia-W, and I will follow them in this respect. Since the sense of asymmetry is most striking in this case, we can expect objections from asymmetry to succeed here if anywhere.
} 
this is precisely as good a way of satisfying this requirement as is actually paying attention to what you believe and acting accordingly. (Schroeder 2009: 227. See also 2004: 349).

Schroeder's observation is that there is an asymmetry between deciding to what to do on the basis of your normative beliefs and giving up those beliefs because you are not going to act on them. ${ }^{9}$ There is an intuitive sense in which the former is a reasonable way of going about things, while the latter is not. Related points can be made about Means-End-W. For instance, we might think it is typically reasonable to decide to take the means because you are going to pursue the end, but typically unreasonable to give up the end because you are not going to take the means. The former is part of what it is to be resolute, the latter is to be irresolute. Furthermore, as stated, MeansEnd-W offers a third option - give up the means-end belief. And it certainly seems unreasonable to do that because you are not going to take the means (Schroeder 2004: $346){ }^{10}$

It is clear that these are basing asymmetries: asymmetries in the reasons for which you could form and revise your attitudes so as to comply with rational requirements. Schroeder's argument is therefore vulnerable to the strategy outlined. The Wide-Scoper can explain the asymmetries by appealing to independent basing principles. In this section I develop a reply of this kind.

It will be helpful to begin by clarifying the asymmetry at issue. To follow your conscience is to form and sustain your intentions in light of your beliefs about what you ought to do. ${ }^{11}$ Conscience-following is thus a relation between attitudes - a normative belief and an intention. By contrast, rationalization, in Schroeder's

\footnotetext{
${ }^{9}$ Schroeder says 'moral beliefs', but the heart of the worry applies more generally.

${ }^{10}$ Note though that not all versions of the Wide-Scope view offer this option in the means-end case (Way 2010).

${ }^{11}$ Talk of 'conscience-following' is most natural if the beliefs in question are moral. But since the problem is more general, I shall adopt an artificially broad use of this expression.
} 
description, involves dropping a normative belief because you are not going to act on it. At this level of description, this is a relation between a belief and a putative fact, rather than a relation between attitudes. But I take it that rationalization will at least involve a relation between attitudes. It involves dropping the belief that you ought to A on the basis of the belief that you will not A. In what follows, I understand rationalization in this way.

Thus understood, Schroeder's observation is that there is an asymmetry between two psychological relations, each of which ensures conformity with Enkrasia-W. The question is why this is supposed to be a problem for the Wide-Scope view. Schroeder says that '[a]ccording to the Wide-Scope view, [rationalization] is precisely as good a way of satisfying [Enkrasia-W] as is actually paying attention to what you believe and acting accordingly' (2009: 227). The thought seems to be that since the Wide-Scoper holds that conscience-following is reasonable because it brings you to comply with Enkrasia-W, he must take rationalization to be reasonable too, since that also brings you to comply with Enkrasia-W.

This is a tempting line of thought, but it should be resisted. The Wide-Scoper need not hold that conscience-following is reasonable just because it brings you to comply with Enkrasia-W. More generally, Wide-Scopers can reject the implicit suggestion that mere compliance with Wide-Scope rational requirements is sufficient for rationality. The Wide-Scope view can allow that rationality also requires you to form and sustain your attitudes in the right sort of way, where this is specified by independent basing principles. If conscience-following involves appropriate basing, while rationalization does not, these principles will help explain why one, but not the other, is typically reasonable. 
There are independent grounds for thinking that we need basing principles. If you have an attitude, we can ask at least two things. We can ask whether it is rational to have that attitude, and we can ask whether you are rational in having that attitude. These things can come apart. Even if it is rational to believe that $\mathrm{p}$, you are not rational in holding this belief if it is a product of wishful thinking, or an obvious fallacy. Rationally holding an attitude is not simply a matter of having an attitude it is rational to hold. Rational requirements must be supplemented by basing principles.

Once such principles are accepted, it is very plausible that they will explain the rationalization asymmetry. For the problem with rationalization is a basing problem. What makes rationalization unreasonable is that it involves giving up a belief for the wrong sort of reasons. ${ }^{12}$ And part of what makes conscience-following reasonable is that it involves forming an intention on an appropriate basis. A full explanation of this would require a general account of when a mental state is an appropriate basis for forming or revising an attitude. But it is very plausible that any adequate account will imply that normative beliefs are the right sort of basis for intention, whereas predictive beliefs are not the right sort of basis for dropping normative beliefs.

This suffices to counter Schroeder's objection. But the case can be bolstered if we briefly consider what plausible basing principles might look like. I will note two kinds of account. The first understands appropriate basing in terms of preservation of correctness, by analogy with the way in which valid arguments preserve truth. On this kind of account, an attitude is an appropriate basis for another attitude only if, necessarily, if the former attitude is correct, the latter is, too. ${ }^{13}$ What constitutes

\footnotetext{
${ }^{12}$ Thus, rationalization is problematic even in cases in which you ought to give up the relevant belief. Even if you ought to stop believing that you ought to A, something will be going wrong if you stop believing that you ought to A because you are not going to A.

${ }^{13}$ For something like this, see Wedgwood 2007: chap 4.
} 
correctness will depend on the attitude in question. But if we assume that beliefs are correct only if true, that intending to $\mathrm{A}$ is correct if you ought to $\mathrm{A}$, and that it is sometimes incorrect to drop a true belief, then conscience-following is correctnesspreserving, but rationalization is not. For if you correctly believe you ought to A, it will be true that you ought to A, and so correct to intend to A. And since you do not always do what you ought, it can be correct to believe that you will not A, but incorrect to drop the belief that you ought to A. So this account allows that conscience-following involves appropriate basing, and implies that rationalization does not.

A second kind of account ties appropriate basing to normative reasons. This is a natural thought. Although an agent's reasons for believing or intending are not necessarily normative reasons, it is plausible that they are good reasons only if they are - or if true would be - normative reasons. This suggests an account of basing on which a belief is an appropriate basis for another attitude only if its content, if true, would be a normative reason for that attitude. And a belief is an appropriate basis for dropping an attitude only if its content, if true, would be a normative reason against that attitude. Rationalization fails the latter condition, since the fact that you will not A is typically not a reason not to intend to A. Conscience-following meets the former, if the fact that you ought to $\mathrm{A}$ is a reason to intend to $\mathrm{A}$.

So there are different basing principles that the Wide-Scope view might appeal to in explaining the rationalization asymmetry. But to repeat, the Wide-Scoper need not take a stand on which basing principles are correct, in order to distinguish between conscience-following and rationalization. The key move is to reject the assumption that mere compliance with Wide-Scope rational requirements is sufficient for rationality. Once this move is made, it is very plausible that the rationalization 
asymmetry will be explained by the correct basing principles, whatever they turn out to be.

\subsection{Collapse Problems}

Before moving on, it is worth addressing a worry one might have about the strategy pursued here. The strategy has been to appeal to principles independent of the WideScope view to explain the rationalization asymmetry. Schroeder discusses a reply of this sort. The version he considers holds that 'though changing [your] beliefs is not ruled out by [Enkrasia-W], it is ruled out by some other principle governing theoretical reason, which says not to change your beliefs about what you ought to do, or some such thing' (2009: 227, italics deleted). He objects that such principles threaten to collapse the Wide-Scope view into the Narrow. For if you believe you ought to A, then the only way to comply with both Enkrasia-W and the requirement not to change your belief is to intend to A. It seems to follow that you are rationally required to intend to A. But that is just the Narrow-Scope requirement that EnkrasiaW was supposed to replace. ${ }^{14}$

The strategy outlined here avoids this problem. Rationality requires you not to form and revise your attitudes on inappropriate grounds. For instance, rationality requires you not to drop the belief that you ought to A on the basis of believing you will not A. But it is possible to comply with this and with Enkrasia-W without intending to A. So we cannot infer that you are rationally required to intend to A.

However, we might think that the Wide-Scope view collapses in a different way. If basing principles help explain what is reasonable about conscience-following

\footnotetext{
${ }^{14}$ Schroeder 2009: 227. See also Finlay forthcoming, section 2. And see Broome (2007a: 17-18) for doubts about the inference this argument relies on.
} 
and unreasonable about rationalization, we might wonder what role Wide-Scope requirements themselves play. It might seem that the present attempt to defend WideScope requirements leaves them redundant. But that is not so. While basing principles help explain what is reasonable about following your conscience, they do not tell us that it is irrational not to follow your conscience. Akrasia need not involve an attitude held on an inappropriate basis - it need not be a basing problem. And yet something has gone wrong with the akratic agent. That is just what Enkrasia-W tells us - that the akratic agent violates a rational requirement. The same goes for the other local irrationalities, and the corresponding Wide-Scope requirements. This means that Wide-Scope requirements are importantly asymmetrical: you are necessarily irrational if you violate a requirement, but not necessarily rational if you comply with a requirement. It is because of this that the Wide-Scope view can accommodate the rationalization asymmetry. ${ }^{15}$

\section{The Reasoning Test}

Niko Kolodny recognizes that mere compliance with Wide-Scope requirements is not sufficient for rationality:

\footnotetext{
We judge that a person is rational or irrational not only in virtue of the state he is in at a given time, but also in virtue of how he transitions from one state to another over time. A bolt of lightning might jolt me out of a state in which I have two inconsistent beliefs and into a state in which I lack one or both of them. Although this process might be said to take me from an irrational state to a rational one, it would not, itself, be rational. By contrast, it would be rational
}

\footnotetext{
${ }^{15}$ Of course, the Narrow-Scope view also tells us that the akratic agent is irrational. The advantage of the Wide-Scope view is then just that it does not have the implausible consequences of the NarrowScope view. This, of course, is just the standard argument for the Wide-Scope view, rehearsed at the start of this paper.
} 
of me to revise one or both of these beliefs in light of the evidence against them. In other words, one is rational or irrational not only in virtue of the attitudes that one has at any given moment, but also in virtue of how one forms, retains, and revises one's attitudes over time. (2005: 517)

Kolodny's point is about the processes by which we form and revise our attitudes over time. But he might have made the same point about the reasons for which we hold attitudes at a time. You might be less than fully rational in having attitudes that violate no Wide-Scope requirement, if those attitudes are held for bad, or no, reasons. Wide-Scope requirements must be supplemented with basing principles.

I have argued that acknowledging this point allows the Wide-Scoper to accommodate the rationalization asymmetry. But Kolodny argues that there is a problem for the Wide-Scoper here. For Kolodny holds that the Wide-Scope view cannot accept an important connection between the attitudes we are rationally required to have, and the processes by which we form and revise our attitudes. This connection is stated in Kolodny's Reasoning Test:

You are rationally required (either not to have A, or not to have B) only if, from a state in which you have conflicting attitudes A and B, (i) you can reason from having A to dropping B and (ii) you can reason from having B to dropping A. (cf. Kolodny 2005: 521). ${ }^{16}$

As stated, the Reasoning Test only applies to rational requirements governing conflicting attitudes. It does not apply to requirements governing local irrationalities

\footnotetext{
${ }^{16}$ Kolodny's statement of the test requires you to be able to reason 'from the content of A to dropping B' (2005: 521, my italics). As Hussain ms, section 4.2 observes, Kolodny's notion of reasoning 'from the content' raises certain difficulties. For present purposes, these difficulties are not crucial: the argument only requires that reasoning must begin from an attitude, and not the lack of an attitude.
} 
involving the lack of an attitude. But Kolodny intends the test to apply to such requirements, and it is easily modified to do so:

You are rationally required to (have B, if you have A) only if, from an irrational state in which you have A but not B, (i) you can reason from having A to forming B and (ii) you can reason from not having B to dropping A.

So modified the test makes trouble for Wide-Scope requirements such as EnkrasiaW. ${ }^{17}$ Reasoning is a process of 'acquiring, retaining and revising attitudes on the basis of the contents of other attitudes' (2005: 520). Reasoning must therefore begin from an attitude. It cannot begin from the mere lack of an attitude: you cannot reason from not having attitude B to dropping attitude A. (You can reason from the belief that you lack an attitude, but Kolodny's test requires more than this). It follows that there cannot be rational requirements of the form of Enkrasia-W.

\subsection{Against the Reasoning Test}

I will argue that the Wide-Scoper should reject the Reasoning Test. I will begin by showing why the Wide-Scoper should reject Kolodny's argument for the Reasoning Test. The same point will show that the Wide-Scoper should reject the test itself.

Kolodny argument for the Reasoning Test begins with the Rational Response Test:

\footnotetext{
${ }^{17}$ As formulated, the Reasoning Test only applies to requirements governing a single antecedent attitude. But a variant of the test seems to rule out requirements involving more antecedent attitudes, such as Means-End-W and Closure-W.
} 
You are rationally required (either not to have A, or not to have B) only if (i) you can rationally resolve the conflict of having A and B by dropping B and (ii) you can rationally resolve it by dropping A. (cf. Kolodny 2005: 520).

Kolodny holds that rationally resolving an irrational state must involve reasoning, in the above sense (2005: 520). So it follows from the Rational Response Test that you must be able to rationally resolve the conflict of having A and B, by (i) reasoning to dropping B and (ii) reasoning to dropping A. However, since the state of having A and B is a local irrationality, we cannot assume any other attitudes you might have. So there must be starting points for these processes of reasoning within the irrational state itself. That is, it must be possible to reason from having A to dropping $\mathrm{B}$, and from having B to dropping A. So the Rational Response Test implies the Reasoning Test.

However, the Wide-Scoper should resist this argument at its first step. For the Rational Response Test is in tension with the now familiar point that basing bears on rationality. An attitude can be rational in virtue of its basing even if it is an element of a local irrationality. For instance, you might be entirely rational in believing that you ought to A - indeed, you might know that you ought to A - even while you are akratic with respect to this belief. (The problem with local irrationality is in the combination). This means that the Rational Response Test requires you to be able to rationally drop even rational attitudes - even, for instance, beliefs that amount to knowledge. And this is surely too demanding. It cannot be a requirement on rationally holding an attitude that you be able to rationally drop that attitude.

The same kind of consideration applies directly to the Reasoning Test. If it need not generally be possible to rationally drop each of the attitudes involved in a 
local irrationality, it need not be possible to do so by reasoning - let alone by reasoning on the basis of the states that constitute the local irrationality. The Reasoning Test should be rejected. ${ }^{18}$

\title{
3.2. State-Requirements and Process-Requirements
}

The discussion so far takes no account of Kolodny's distinction between state- and process-requirements. But it might be thought that if rational requirements are process-requirements, the Reasoning Test cannot be rejected so quickly. If this were so, we would only have a defence of Wide-Scope state-requirements. But I will argue that it is not so. The above argument goes through whether rational requirements are state- or process-requirements.

Kolodny introduces the state/process distinction by observing that rationality has a dynamic element. Rationality does not only require us to have coherent attitudes at a time. It also requires us to rationally form and revise attitudes over time. Therefore:

\begin{abstract}
We should...distinguish between 'state-requirements', which simply ban states in which one has conflicting attitudes, and 'process requirements', which say how, going forward, one is to form, retain, or revise one's attitudes so as to avoid or escape such conflicting states. (2005:
\end{abstract} 517).

As I have been interpreting them, Wide-Scope requirements are state-requirements. Enkrasia-W, for instance, tells you not to be in the state of believing that you ought to

\footnotetext{
${ }^{18}$ It might be thought that this response gives rise to another version of the Collapse problem (2.1). For if your antecedent attitude is rational, and you have no way of dropping this attitude by reasoning, then the only way forward is to form the consequent attitude. And this may be thought to imply that the consequent attitude is rationally required. However, this would show only that Narrow-Scope requirements apply when the antecedent attitudes are rational (and cannot be rationally dropped). But this is not implausible in the way that unqualified Narrow-Scope requirements are.
} 
A while not intending to A. It does not tell you how, going forward, to form, retain, or revise your attitudes. So if rational requirements are process-requirements, they must be reformulated. Kolodny suggests that Enkrasia-W might become:

(Enkrasia-WP1) If you believe that you ought to A but do not intend to A, then you are rationally required to either (i) form the intention to A on the basis of your belief that you ought to A or (ii) give up the belief that you ought to A on the basis of your lack of an intention to A. (cf. Kolodny 2007a: 373).

Enkrasia-WP $\mathrm{W}_{1}$ suggests a new argument for something like the Reasoning Test. For it is plausible that Enkrasia- $\mathrm{WP}_{1}$ is a genuine requirement only if it is possible to do what (ii) says.

However, it is not clear why Wide-Scopers should accept Enkrasia-WP $\mathrm{W}_{1}$ as the reformulation of Enkrasia-W. Process-requirements are concerned with the attitudes to form or revise going forward - they are diachronic, rather than synchronic. But Enkrasia-WP $\mathrm{W}_{1}$ not only calls for you to form or revise attitudes, but to do so on a particular basis. It is not clear why process-requirements must be this specific. If the point is simply to call for a response, there is a much simpler way to reformulate Enkrasia-W:

(Enkrasia-WP2) If you believe that you ought to A but do not intend to A, then you are rationally required to either (i) form the intention to A or (ii) drop the belief that you ought to A. 
And if this is the correct formulation, it is unclear why it must always be possible to drop the antecedent belief by reasoning. Indeed, the same considerations raised in the last section apply. If your antecedent belief is rational, then you may have no other attitudes which allow you to rationally drop this belief. Enkrasia- $\mathrm{WP}_{2}$ gives no support to the Reasoning Test.

Kolodny's arguments that rational requirements are process-requirements do not favor Enkrasia-WP $\mathrm{W}_{1}$ over Enkrasia- $\mathrm{WP}_{2}$. These arguments turn on the idea that rational requirements are normative: 'the very idea of a state-requirement is questionable. If rational requirements are normative, deontic, or response guiding, then they call for the subject to respond in a certain way (2005: 517). Again, 'some requirements of rationality are normative or deontic...they can function as advice or guide your deliberation... state-requirements are not normative, in this sense, since they do not tell you to do anything' (2007a: 371-2). However, both Enkrasia-WP ${ }_{1}$ and Enkrasia- $\mathrm{WP}_{2}$ are normative, in this sense: both call for you to respond in a certain way. $^{19,20}$

Furthermore, there are independent grounds for preferring Enkrasia- $\mathrm{WP}_{2}$ to Enkrasia-WP $\mathrm{P}_{1}$. The latter implies that you fail to do something rationality requires if, when you believe you ought to A, you form the intention to A on the basis of something other than this belief. But this seems unnecessarily restrictive. Suppose that you form the intention to $\mathrm{A}$ on the basis of belief in considerations that are reasons to

\footnotetext{
${ }^{19}$ Kolodny does briefly consider requirements along the lines of Enkrasia-WP $\mathrm{W}_{2}$ He objects that these would be requirements to 'avoid or escape [an irrational state] in any way one likes' (2005: 517. cf. also 2007a: 372). But this seems to me a mistake. As we saw in section 2, independent basing principles may constrain the rational ways to escape a local irrationality.

${ }^{20}$ Some might worry that there is no significant distinction between Enkrasia- $\mathrm{WP}_{2}$ and Enkrasia-W. After all, since Enkrasia-W applies at all times, it implies that: if at time t you believe you ought to A but do not intend to $\mathrm{A}$, then at $\mathrm{t} 1$ you are rationally required to either intend to A or not believe that you

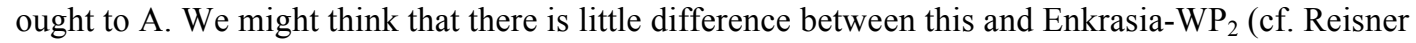
2009). However, if there is no significant distinction between Enkrasia-W and Enkrasia- $\mathrm{WP}_{2}$, the Wide-Scoper can reject Kolodny's claim that Enkrasia-W is not response-guiding, since Enkrasia-WP $\mathrm{P}_{2}$ is clearly response-guiding.
} 
$\mathrm{A}$, or on the basis of intending to A and believing that Bing is a good way to A. It seems like you might be rational in forming your intention in this way, even if you also believe that you ought to A. If so, that is another reason for the Wide-Scoper to prefer Enkrasia-WP $\mathrm{WP}_{2}$ to Enkrasia-WP $\mathrm{W}_{1}$

I conclude that Wide-Scopers can accept that rational requirements are process-requirements and still reject the Reasoning Test.

\section{Conclusion}

I have discussed two types of asymmetry and argued that neither grounds a compelling argument against the Wide-Scope view. A modest version of the WideScope view - one that allows that particular attitudes can be rationally required, and that rationality involves forming, holding and revising attitudes for appropriate reasons - can accommodate the asymmetries. Of course, this does not amount to a complete defense of the Wide-Scope view. There may be other compelling objections to Wide-Scope requirements, and it may be that their work can be done by other principles. I am here agnostic about this. But whatever else is wrong with the WideScope view, it is not the symmetry of its rational requirements. ${ }^{21,22}$

\section{References}

Broome, J. 1999. Normative Requirements. Ratio 12 (4), 398-419.

\footnotetext{
${ }^{21}$ I discuss other objections to the Wide-Scope view in Way (2010).

${ }^{22}$ This paper has benefited greatly from comments I have received from John Broome, Niko Kolodny, Errol Lord, Josh May, Alan Millar, Ian Nance, Andrew Reisner, Mark Schroeder and an anonymous referee. Many thanks to all.
} 
2005. Does Rationality Give Us Reasons? Philosophical Issues 15 (Normativity), 321-37.

2007a. Requirements. In Homage à Wlodek: Philosophical Papers Dedicated to Wlodek Rabinowicz, ed. Toni Rønnow-Rasmussen, Björn Petersson, Jonas Josefsson and Dan Egonsson, 2007. http://www.fil.lu.se/hommageawlodek. 2007b: Wide or Narrow Scope? Mind 116 (462): 359-70.

Brunero, J. 2010. The Scope of Rational Requirements. Philosophical Quarterly 60 (238): 28-49.

Finlay, S. forthcoming. What Ought Probably Means, and Why You Can't Detach It. Synthese.

Hussain, N. ms. The Requirements of Rationality. Manuscript of 12 August 2007. Kolodny, N. 2005. Why Be Rational? Mind 114 (455): 509-63. 2007a. State or Process Requirements? Mind 116 (462): 371-85. 2007b. How Does Coherence Matter? Proceedings of the Aristotelian Society, 107 (1), 229-263.

Korsgaard, C. 2009. The Activity of Reason. Proceedings and Addresses of The American Philosophical Association 83 (2): 23-43.

Raz, J. 2005. The Myth of Instrumental Rationality. Journal of Ethics and Social Philosophy 1, 2-28.

Reisner, 2009. Unifying the Requirements of Rationality. Philosophical Explorations 12 (3): $243-260$.

Schroeder, M. 2004: The Scope of Instrumental Reason, Philosophical Perspectives (Ethics) 18: 337-64.

2009: Means-End Coherence, Stringency, and Subjective Reasons, Philosophical Studies 143: 223-248. 
Way, J. 2010. Defending the Wide-Scope View to Instrumental Reason.

Philosophical Studies 147: 213-33.

Wedgwood, R. 2007. The Nature of Normativity. Oxford: Oxford University Press. 